\title{
Students, Faculty, And Administrators' Perception Of Students' Evaluations Of Faculty In Higher Education Business Schools
}

Franklin D. Gaillard, (E-mail fanklin.gaillard@hamptonu.edu), Hampton University

Sonja P. Mitchell, Hampton University

Vahwere Kavota, Hampton University

\begin{abstract}
This literature review analyzes students' evaluations of faculty in higher education business schools. Particularly, differences in perception amongst students, faculty and administrators are examined across variables deemed significant by scholars.

Each academic year students are requested to complete faculty evaluation forms for the classes they take at almost every university (Mohammad Ahmadi, Marilyn M. Helm, Farhad Raiszadeh [2001]. Numerous approaches and research related to students' evaluations of faculty have been conducted and have led to different results and conclusions. Students' evaluations of faculty have been used primarily for faculty promotion, salary raises, tenure, teaching efficiency, retention or faculty dismissal. Nevertheless, students, faculty and administrators have mixed feelings and perceptions about the students' evaluations of faculty. This paper examines the views and perceptions of business major students and faculty at the School of Business at Hampton University. Business students and faculty will be asked to complete a various survey instruments. Results will be examined and presented.
\end{abstract}

\section{INTRODUCTION}

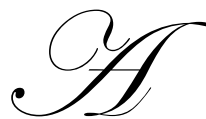

lmost every university or college around requests students to complete faculty evaluation forms for their classes. The evaluation timing and timeframe varies from one university to another. Student evaluations of faculty are done on a quarterly, semester or yearly basis. Despites those differences, a variety of opinions and views for and against those evaluations persist.

Some faculty believes that student evaluations of faculty are unnecessary, questioning whether students are trained in making good judgment about their classes and methodology used in teaching those classes. Other instructors judge their peers who obtain high student evaluation marks as being easier graders and easy goers. They also think that elective course professors receive high scores compared to those who teach required or major courses. Those instructors also believe that long-term benefits from the class by the students such as knowledge, retention, and application of different concepts learned are more important than immediate gratification from student evaluation and are not reflected in the evaluation outcome.

On the other hand, other faculty and administrators support the idea that student evaluations are crucial, valid and should be integral part in judging faculty teaching performance and effectiveness. They also believe that those evaluations are important in instructor's promotion, salary increases, and retention, pre-tenure and post-tenure reviews. The same faculty argues that student evaluations should not be used for feedback only regarding their teaching, but also as indicators of strengths and weaknesses within their course, department and/or program. 
Students seem perplexed about the rationale and assessment of student evaluations of faculty. Some of them fill those forms out in a half-hearted manner believing they will not lead to changes in course content, faculty instruction methodology and faculty retention or firing. Other students make comments they believe are disregarded. Faculty also thinks that no matter if the student loves or dislikes the course will write comments, however always the majority never writes comments. Therefore, the faculty believes the majority non-expressed comments are most representative and valuable. Other schools that use computerized evaluation forms do not provide space for comments; consequently students are limited in expressing their views. Other schools may also choose to publish their evaluations results for students' information while others do not.

Faced with varied opinions about student evaluations of faculty, the topic deserves further research. This paper evaluates different perceptions of the School of Business students, administrators and faculty at Hampton University toward administrative use of students' evaluations of faculty. Results will be used to develop and/or improve faculty evaluation tools. Suggestions will assist in the implementation at other business schools and colleges overall.

\section{USE OF EVALUATION}

Students' evaluations of faculty have been used and widely recognized as an effective tool of evaluating faculty's overall performance in higher education for decades. Blank [1978] p. 124, indicated that in 65 percent of higher education institutions, all or nearly all departments have implemented student evaluations. In a survey of faculty evaluation practices amongst AACSB schools, Lein and Merz [1978] p. 21, report that 70 percent of all schools responding use formal student evaluations in assessing teaching effectiveness. Teaching evaluations are used as an effective means of measuring a professor's teaching performance as perceived by students. Several studies (Caldwell\&Jenkins, 1985; Cashin, 1988; Marsh, 1984; Mims\&Heller), [1987], have shown that the student rating of professors has been described as the most valid measure of teaching effectiveness, although the validity of student evaluations has been controversial and a recurrent research theme due to the variety of measuring methods Gaski, [1987]. Wallace, James J; Wanda A. Wallace, [1998], indicate that overall, students are thought to convey honest perceptions of the professor's teaching abilities; thus, the evaluation is presumed to be statistically reliable, valid, and free from general bias. The rhetoric of defenders of the student evaluation as a tool includes the assertion that the students are the consumers, that education cannot occur if the students are not satisfied, that this is just one of several tools used for evaluations and why should one not expect that an assessment by all students in a class would fairly reflect an educational experience? No harm, no foul, is one perspective, and another is a claim that if all our faculty maintains high evaluations, then we must indeed be a fine academic institution that values teaching.

Although faculty evaluations seem to be an important topic, researchers have expressed concerns related to teaching effectiveness. One of the concerns is the accuracy of evaluations and the usefulness of teaching evaluation with particular concern related to the reliability and validity of the overall measurement process. Some faculty members and administrators express a great mistrust of students rating. Gomez-Mejia and Balkin [1992] state "teaching ratings by students do not reflect true teaching performance; they are basically a popularity contest". Many people do not think that teaching evaluation is reliable and valid. Lorraine P. Anderson and Lawrence P. Shao [2002], one of the knottiest problems facing business school administrators is how to evaluate the teaching effectiveness of their professors. The problem is compounded because it can be difficult to know how to weigh various sources of data - including student evaluations, peer evaluations, and teaching portfolios. Since teaching evaluations often are used to determine whether a professor deserves promotion or tenure, it is critical that administrators carefully and fairly interpret all the data available to them. Moreover, despite strong feelings, teaching effectiveness is cited as the single most important factor in overall faculty evaluations by the Deans of American Assembly of Collegiate Schools of Business (AACSB)-accredited schools, Seldin [1985], and student evaluation of instructor is one of the most widely used methods of measuring teaching effectiveness in postsecondary education, Abrami, and Cohen [1990]; Cashin [1988], Clayson [1999]; Nerger, Viney, and Riedel [1997]; Seldin [1993].

The use of faculty evaluation differs from one institution to another and is used for different purposes in most institutions of higher learning. Dunegan, Kenneth J. [2003], states that the information from the Student Evaluations of Teaching Effectiveness (SETs) is used by the school administration, along with other input to reach two goals. The 
first goal is to help make summative decisions such as wages and salaries raises, promotion, tenure, reappointment, etc. The second goal is to help make formative recommendations such as addressing faculty weaknesses, etc. Successfully accomplishing either of these objectives, however is predicated on receiving input that is accurate and reliable. It comes as no surprise, then, that considerable effort has been invested over the years to develop SET instruments that ask the relevant questions and provide the appropriate framework so that students will have the opportunity to furnish the accurate and reliable input we seek (see, for example, the work of Marsh and colleagues: Marsh\&Roche, [1997, 2000]. However, having the correct instrument does not guarantee that the instrument will be used in the manner intended, Mohrman\& Lawler [1983].

Furthermore, the results of a national survey of economics departments by Becker and Watts (1999) indicate that the weight placed on student evaluations of teaching represents $50-60 \%$ of the overall assessment of teaching performance in annual raises, promotion and tenure decisions.

A potential benefit of using student evaluations is an increase in teaching effort by professors, resulting in high student knowledge. Stratton et al. (1994) document that the use of student evaluations induces changes in professor's teaching behavior. Moreover, Brickley and Zimmerman (1999) provide evidence of improved student ratings at the William E. Simon Graduate School of Business Administration of the University of Rochester when there was a shift towards greater emphasis on teacher.

Wallace and Wallace (1998) however argue that the use of student evaluations as a tool to measure professors teaching performance may have negative consequences. They also argue that the use of student evaluations has led to a reduction in student knowledge and manipulation of grades, which is consistent with an increase in the number of students receiving As and Bs in the last two decades. (e.g., Cole, 1993; Dreyfyss, 1994; Beaver, 1997. Therefore, the increases emphasis on student evaluations may lead professors to manipulate grades to obtain higher student ratings, rather that increase their teaching effort. Consistent with this view, Becker and Watts (1999) claim (p. 344) 'that the widespread use of students evaluations of teaching has led to a decline in education standard cannot be ignored'.

Numerous studies suggest why students should be given a role in the evaluation process. First, Donald Roush (1976, p.1) cites research results which suggest that students can clearly discriminate among the teaching performance of different instructors. For example, Frey (1974) compared 13 different instructors who were rated by students in two multi-section calculus courses and found that students were consistent in selecting the same teachers as the best and worst instructors. Waldo (1974, p.12 ) cites research which he has substantiated with his own experience and concludes that ratings given college teachers by their students are consistent with those made by trained, experienced observers. Second, support for student evaluation is a tangible sign that faculty and administrators recognize the importance of student involvement in shaping an institution's goals and practices. And third, student evaluations provide the only direct means of gathering information about an instructor's teaching. Visitations by other faculty members or administrators create only limited and sometimes artificial information about the instructor's teaching effectiveness.

\section{VARIABLES}

Different variables have always been used in the faculty evaluation. The contents of each evaluation vary greatly depending on its objectives.

A review of research in the Journal of Marketing Education and Marketing Education Review reveals 11 empirical articles during the past 20 years that investigated the topic. Cumulatively, this literature addresses issues such as halo effects (Orsini 1988), class size effects (Dommeyer 1997; Guseman 1985), generalization (Wheeler and Geurts 1986), stability of instruction (Bharadwaj, Futrell, and Kantak 1993, and teaching experience (Clayson 1999).

Most studies of student's evaluation of faculty in terms of methodology use factor analysis, inter-item correlation, multiple regression, and multivariate analysis of variance (e.g., Brightman, Elliot, and Bhada 1993; Centra 1977; Doyle and Whitely 1974; Frey, Leonard, and Beatty 1975, Linn, Centra, and Tucker 1975; Loftin 1993; Marsh 
and Roche 1992; Schrader 1988; T.C. Wilson and P.A. Wilson 1977). These statistical methods, however, "share one common limitation. Each technique can examine only a single relationship at a time" (Hair et al, 1995, p.671).

Student - evaluation-of-instructor studies involving the marketing discipline also rely on these more traditional statistical methods. For example, almost half of the articles published use factor analytic techniques to investigate different aspects of teaching (Bertsch and Peek 1982; Clayson and Haley 1990; Grunwald and Ackerman 1986; Mark 2000; Ortinau et al. 1989).

Few studies (e.g., Clayson and Haley 1990; Marks 2000; Stringer and Irwing 1998) use structural equation modeling to assist in identifying the relationships between the factors. The use of structural equation modeling helps the researcher to avoid "jumping to simple conclusions from their data, using only simple OSL solutions, and being subject to nomological errors that can plague correlation studies" (Clayson and Haley 1990, p.12). In addition, structural equation modeling allows the researcher to further test the major relationships between variables (Marks 2000).

Other research and surveys suggest different criteria to be considered in faculty evaluation. For example, a survey of AACSB members was designed to determine what components most deans and department heads believe should be considered in faculty evaluations. The survey suggests that in general, deans and administrators tend to look most closely at a professor's depth of knowledge, student evaluations, technical ability, and teaching skill when evaluating teaching effectiveness. The same survey suggests that: The most single most and extremely important element in faculty effectiveness is the professor's current knowledge of field. Stakeholder feedback is also crucial when it comes from students. Student evaluation scores and student written comments ranked as the most important elements. Peer evaluations are more important than a dean's evaluation, but less important than the chair's evaluation. According to the majority of respondents, evaluative classroom visits by administrators or faculty are only somewhat important or not important at all. Intellectual contributions are not valued as highly as many people think. The teaching portfolio - though gaining popularity in recent years - is not the best measure of teaching effectiveness. Administrators do not appear to be especially concerned about class enrollments, grade distribution, or drop rates. It pays to be tech-savvy. Respondents rated a professor's use of technology as more important factor than colleagues' opinions, grade distribution, course notebooks, course level, course type, class enrollment, and drop rate. Class teaching is the most important element of overall annual faculty performance, rated as extremely important by the correspondents. Within student evaluations, professors' preparation and communication skills are the most important aspects of their teaching. Respondents believe that, in comparing the mean scores from student evaluations, the department mean should carry the most weight, followed by the discipline mean. They consider the college mean and university mean far less important. (Lorraine P. Anderson and Lawrence P. Shao, BizEd p. 36-38, nov-dec.2002).

AACSB members who completed the survey noted that faculty evaluations also should be tied to the mission of the institution. This can be problematical, as several respondents indicated, when schools with teaching missions are asked to place significant emphasis on intellectual contributions. One of the reasons faculty evaluations might be so problematic is that many administrators perceive that every professor brings some value to the school. One dean said, "I try to consider all aspects of each faculty's contribution to our overall mission. Not everyone makes strong contributions in the same areas, but everyone has something of value to offer."

Other researches suggest that student evaluations are multidimensional in the measurement of various aspects of teaching effectiveness. Some variables such as communication skills, attitude toward the student, knowledge of the subject, organizational skills, enthusiasm, fairness, flexibility, and encouragement of the student are identified as strongly related to teaching effectiveness. On the other hand, variables such as the grade received, size of the class, time of the day the class is taught, are other variables used for teaching effectiveness. (Burdsal\&Bardo, 1986; Cashin \& Slawson, 1977; Tang, 1997; Wotruba\&Wright, 1975.

When considering the content of the student evaluation form, Eble (1970) identifies three key considerations that are peripheral. The first consideration is that of objectivity. Eble recommends the inclusion of students, faculty, and administrators in the construction of the questionnaire as a guard against any sub-group biasing the instrument and subsequently the data to be obtained by it. The second key consideration is coverage. The evaluation form should 
be tailored to fit specific colleges, departments or individual combinations of faculty members. Finally, the proper timing of the questionnaire's use must be considered.

Research has also mentioned that the widespread of computers and the availability of the internet, both on campus and off campus has provided students with numerous learning opportunities. However, faculty and students have expressed different opinions about its use in faculty evaluation compared to the traditional faculty evaluation. Some of the opportunities cited have been quick access to instructors, classmates, databases, libraries, and lecture materials.

The traditional 1-day- -in class evaluation of instructors via optically scanned form may eventually give way to evaluation via internet, allowing for extended periods of student evaluation time. The on-line method promises more convenience to students and ease of use for administrators (Layne, DeCristoforo, \& McGinty, 1999). Although electronic surveys are a fairly recent technique, they have been compared with traditional survey methods and been proven effective across a variety of organizational applications such as market research, personal evaluations, and psychological counseling (Sproull\&Kiesler, 1990; Rosenfeld, Booth-Kewley,\&Edwards, 1993). Until last few years, there has been absence of published research comparing on-line student evaluations of faculty with traditional inclass paper and pencil-methods. (Curt J. Dommeyer, Paul Baum, \&Robert W. Hanna).

A recent study comparing these two methods was conducted by Layne et al. (1999). The researchers studied both graduate and undergraduate students, the majority, the majority of whom were in engineering-related disciplines and were computer literate. They concluded that students had high level of satisfaction with the electronic (on-line) method of faculty evaluation over the traditional (in-class) method. Voluntary comments suggested that although the on-line method was perceived by students as having less anonymity, they saw it as less wasteful of resources (paper) and class time. An unexpected finding was that students who completed the survey on-line were more likely to provide voluntary comments than students who completed it in class. Overall, it appeared that the method of evaluation did not affect the responses given by students. Nonetheless, the survey results revealed a lower response rate for students using the on-line method (47.8\%) compared with students using the in-class method $(60.6 \%)$. The student attitudes that might account for these response rate differences were not directly determined. The authors suggested that effective use of the on-line method requires greater institutional endorsements and guarantees of confidentiality. They also suggested that incentives may have necessary to achieve higher response rates.

In another comparable study, Baum, Chapman, Dommeyer, and Hanna (2001) compared the in-class and online evaluation methods among business undergraduate students. They found an even larger difference in response rates between the on-line method (32.8\%) and the in-class method (76.8\%) and some tendency toward higher student ratings of instructors with the on-line method.

Students' attitudes toward the traditional methodology of student evaluations have received relatively little research attention. According to Marlin (1987), student satisfaction as a factor in student ratings has been largely ignored. He noted that some students complain that faculty and administrators pay scant attention to student opinions and that teachers do not modify their behavior based on student comments on rating forms. Abboot, Wulff, Nyquist, Ropp, and Hess (1990) stressed that students' willingness to participate in the evaluation method is directly related to their satisfaction with the evaluation process. To increase student participation in the evaluation of faculty members, university administrators must learn students' attitudes toward current and proposed methods for gathering teaching evaluations.

In another study, Curt J. Dommeyer, Paul Baum, and Robert W. Hanna (2002) found that collecting teaching evaluation via the Internet clearly has advantages over the traditional, in-class method of data collection: On-line data collection eliminates paper costs; requires less class time; permits efficient processing of the data; is less vulnerable to influence of the faculty, and can be a fast, easy, and convenient method for students to submit their evaluations. Despite these advantages, the on-line method will not be widely adopted by universities if it cannot overcome some serous hurdles. It was shown in this survey and others that the on-line method produces a lower response rate to the teaching evaluations than the traditional paper-and - pencil method. The lower response rate is most likely related to factors such as fear that responses to the on-line survey may not be anonymous and that the online method can be 
inconvenient, time -consuming, and prone to technical problems. Moreover, the on-line survey may be the victim of student apathy as the majority of the non-respondents to the on-line survey forgot or missed the deadline date.

Many of the impediments to on-line response can be effectively dealt with over time. As students become more computer literate and have greater access to computers, it will be less likely that "inconvenience" and " technical problems" will inhibit survey response.

\section{STUDENT PERCEPTION}

The volume of studies done in the area of student perception is overwhelming. Most universities and colleges ask their students to complete faculty evaluation forms either each semester or at certain times of the year. No matter what the evaluation intervals and processes are, there are many arguments both for and against the evaluations.

Students seem perplexed about the existence of the evaluation. They complete them as soon as they can for they are confident they will make no change.

In one study, Mohammad Ahmadi, Marilyn M. Helms, Farhad Raiszadeh (2001), students seem confused about the purpose and value of the ratings. Some fill them out as quickly as possible believing they will not make any difference in course content, process, and faculty administration of the course. Others write numerous comments hoping they will make a difference.

In another study by Kenneth J. Dunegan, \& Mary W. Hrivnak (2003), students see very little evidence that their performance appraisals have much of an impact. They receive virtually no feedback about their evaluations, nor are there strong, direct, and observable correlations between positive (or negative) Student Evaluations of Teachers (SET) and teacher rewards (or punishments). In most cases, results of teacher evaluations are not published or shared with students at all. Thus, students see very little connection between their evaluations and subsequent outcomes. In expectancy theory terminology, instrumentality- the connection between actions and outcomes - is virtually nonexistent in SET procedures. When instrumentality is low, expectancy theory predicts lower effort, or a greater likelihood that SET' will be completed in a mindless fashion.

Wallace, James J.; Wanda A. Wallace (1998) revisit the adage of "you get what you measure". They argue that student evaluation tool is a measure of students' concurrent happiness index at the end of a course, prior to receiving final grades. That happiness should be reasonably expected to reflect their attitude as to how hard they have worked, their perceived reward for that work, their anticipated assessment by the professor, and the remaining demands on their time from the course at hand. If a course has been rigorous, has often conflicted with other preferred uses of their time, has produced a lower than desired performance assessment for their degree of knowledge to date, and continues to be a demand on their time to prepare for what is expected to be an exacting final examination, the happiness index cannot be expected to be high. Indeed, Wallace, James J. and Wanda A. Wallace were told by the students that if a faculty member's actual teaching effectiveness is to be assessed, students should be asked to perform evaluations prior to any examinations or grading of the students' performance. Students admit that their evaluation of the faculty is directly affected by how demanding that faculty member is in examining and assessing their student performance. If one contemplates such attitudes by the students, then one should at least consider how this feedback might be reacted to by a given member of the academy.

Also while thinking of themselves as mature, even as undergraduates, students doubt that their evaluations concurrent with the painful experiences of hard work and tough assessments by those mentors would have exhibited a high happiness index relative to less demanding evaluators.

\section{FACULTY PERCEPTION}

Faculty have mixed feelings when it comes to student evaluation of faculty. Mohammad Ahmadi, Marilyn M. Helms, Farhad Raiszadeh (2001) in their study state that some faculty finds evaluations by students to be invalid, questioning whether their students, who are not trained in the course material can adequately judge the class or its 
methods. Other faculty finds that those colleagues who are known to be the easier graders, those with the best personalities, or those who teach elective courses receive higher scores from students than those in required or major courses. In addition, there are long-term issues of learning, retention, and benefit from a course that extends well beyond the immediate evaluation that are not reflected in the evaluation results.

Mark Clayton (1998, p.5) quotes William Pallett - Director of the IDEA Center at kansa University in Manhattan, a unit that helps colleagues analyze students' evaluations, as saying "student evaluations should not become the dominant influence in personnel decisions, but all too often do. When that occurs, bad things do happen." Concerning the validity of students' evaluations, Clayton refers to the case of Anthony Greenwald, professor of psychology at the University of Washington at Seattle, whose students' ratings dropped from the very top in one year to the very bottom in the following year, fro the same course while using the same syllabus and same teaching method, as an example.

Marsh et al. (1975) however focused on instructional quality based on performances on standardized final examinations correlated with instructor rating. Their findings suggested that student evaluations are valid measures of instructional quality. Marsh (1984) later used the construct validation approach in evaluating student ratings as a measure of teaching effectiveness, maintaining that teaching effectiveness is multifaceted with no single criterion of effective teaching. His study emphasized the inconclusiveness of student evaluations in general, but still stated that they are useful, but should be used with caution.

Administrators also seem to have mixed reviews on how best to incorporate the students' evaluations in critiquing a faculty member's performance. Should they be used for yearly evaluations, tenure decisions, and posttenure review? Question remain. At some universities, faculty members are the only ones who see the evaluations and may share them with their department heads/chairs and deans only if they choose to do so. They may not be included as part of a faculty member's dossier or teaching notebook.

Other studies believe that student evaluation of faculty could be beneficial to the faculty.

Based on literature review: The original purpose of student evaluations was to provide feedback to the instructor to improve his/her teaching. Now, according to Lein and Merz (1978, p.23) the information is disseminated to various groups within the university structure - the individual faculty member, the Promotion and Tenure Committee, Dean and Chairperson, the Central Administration, faculty peers and the students. This practice bothers those being evaluated. Shades of George Orwell's 1984!

\section{RESEARCH METHODOLOGY DESCRIPTION}

\section{Statement Of Hypothesis}

A review of the literature suggests that students might not truly understand the value of the faculty evaluation program. As such they might not fully participate in the program. This generally means that student might not pay close attention to the scores they assign to a particular faculty member. This leads to the following hypothesis:

H1: Students' perceptions of the value of the faculty evaluation program affects their participation in the process. In the case participation is the dependent variable and value is the independent variable.

To test this hypothesis, a survey of School of Business students will be conducted that measures their responses to the constructs of value and participation. A regression analysis using participation as the dependent variable and value as the independent variable will provide the answer. A strong relationship will show that students need to understand value before they fully participate in the evaluation process. A weak relationship will not show this. A strong relationship between the two constructs would highlight the need to educate the student more fully on the purpose and meaning of the faculty evaluation program. 


\section{Participation}

Participation has been measured by Bettencourt (1997) using a seven point Likert scale which measures the extent to which customer express and active involvement in a process (Bettencourt 1997). The emphasis is on verbal suggestions and feedback about improving service of the faculty evaluation process. This scale is distinct from another use of the construct which means participation where it means active involvement in producing the service. This research suggests that customers make recommendations to improve the service (Brunner et al 2001). The reliability coefficient (coefficient alpha) is .85 and the validity is not explicitly examined. Bettencourt did perform a confirmatory factor analysis (CFA) with items from this scale and two other items which provided support for the three factor conceptualization (Brunner et al 2001). The scale items are worded for the academic context and are given as the first seven items in the survey questionnaire.

\section{Value}

Value or the ability to judge has been tested by Putrev (1991) using a seven point Likert scale (Putrev 1992). This scale measures the degree to which a consumer expresses the ability to judge "good deals" across brands and stores particularly when it comes to shopping (Brunner et al 2001). This can be applied to the academic setting whereby students are asked to judge faculty "good deals" through the faculty evaluation process. The reliability or coefficient alpha of the scale was .76 and validity was not established. The scale items are worded for academic evaluation context and are given as the second seven items in the survey.

\section{Research Design And Methodology}

Using the survey in Appendix A and B, this research tests whether a relationship exists between participation and value in the academic setting at the School of Business at Hampton University. The research will show the nature of the relationship and unite the empirical evaluation with the literature review previously discussed.

\section{Restatement Of Hypothesis}

H1: Student perception of the value of the faculty evaluation process affects their participation in the program.

A statistically significant relationship between the two will reveal the need to educate students about the process and the program to improve their participation. Neither of these concepts has been tested in the faculty evaluation setting.

\section{Description Of Sample And Size}

The research will sample 300 students at Hampton University School of Business classified as either junior and senior undergraduate students. Recommend sample size varies according to the statistical tool employed (Levin and David 1983). For regression analysis the minimum sample size is $50+8(\mathrm{p})$ where $\mathrm{p}$ is the number of independent variables. In this case it would be $50+8(1)$ or 58 as the minimum sample size. Collecting 100 samples should provide at least the minimum sample size even if some samples are incorrectly completed and cannot be counted.

\section{Data Collecton}

The research team conducted a random sample of approximately 300 students at the Hampton University School of Business from April 14, 2005 until April 27, 2005 in the common area between Martin Luther King Building and Buckman Hall. There were 289 usable student responses to the survey and 10 faculty responses to the survey. Since the faculty response was so limited, no inferences will be attempted on the data. Descriptive data of the faculty survey is provided for information only. The student survey coincided with the normal faculty evaluation period which comes very close to the end of the term generally. 


\section{Analysis Of Results}

\section{Factor Analysis}

Using the data set collected, an initial factor analysis of the 289 student responses was conducted to see if the factors obtained could be identified with the constructs of participation and value. Entering arguments for the factor analysis were the 289 survey responses and those questions pertaining to participation and value as discussed earlier.

The analysis used was a principal components factor analysis with varimax rotation and Kaiser-Meyer-Olkin normalization. The Kaiser-Meyer-Olkin measure of sampling adequacy is .79 and the Bartlett's test of sphericity is .000 both of which are acceptable for continued analysis. The rotated factor matrix show two factors which were directly related to the constructs of participation and value. These factor with their associated factor loadings became variables for a later regression analysis.

\section{Coefficient Alpha}

The measure of reliability for the constructs from the data set was .719 got participation and .17 for value.

Regression Analysis

A linear regression analysis was conducted using participation (construct) as the dependent variable and value as the independent variable. The $\mathrm{r}$ square for the regression model is .14 and the F statistic is 48.449 which is significant at $\mathrm{p}=.000$ These statistics indicate that there is a significant statistical relationship between participation in the faculty evaluation process and the value that the students place on the faculty evaluation process itself.

\section{Hypothesis Test}

Based on the above data, the hypothesis is substantiated.

\section{Analysis Of Findings}

There appears to be enough information to warrant a closer look at the faculty evaluation process. It might be an evaluation of the timing of the process or the specific questions being asked. If the students don't see any value in the process, they might not fully participate in it (i.e. pay no attention to the scores that they assign). It may work better if the process is explained early in the student initiation to college life such as indoctrination or Freshman orientation. Based also on the students' comments about the evaluation, the students believe that the teacher evaluation process needs extra work. They think that when a poor overall evaluation occurs, they should be aware of the changes that are being made to correct the problems, such as firing the faculty, letter of notification about poor performance. In the same manner, a teacher receiving an excellent evaluation should receive a public recognition for excellent achievement or increase in salary. The students also think that their comments are not taken into consideration and although they make comments, the teachers still teach and behave in the same way.

Even though the faculty participation was so limited, some faculty stressed that external feedback is not of much use to self-change. Internal feedback is effective. So if you are not performing - you know it - hearing this from the students will not affect change.

Similarly, hearing it from your boss will not affect you either. They also more likely attribute poor performance to incompatible task requirements, "lot-of-that at Hampton University", low skill sets, low work ethic leading to long-term alienation. They also believe that there is a problem for a student evaluating a professor and that only Faculty should evaluate Faculty. Student evaluations undermines social distance and the Professor-Student relationship. 


\section{CONCLUSION}

There is a statistically significant relationship between student participation in the faculty evaluation process and the value that they see in that process. Better education may improve student participation rates.

\section{INFERENCES FROM DATA ANALYSIS}

Based on the above research, it can be inferred that students in other schools at Hampton University feel the same way about the faculty evaluation process. This becomes a suggestion for future research to either prove or disprove the inference.

\section{RECOMMENDATIONS}

1. Educate students about the process and the reasons for it

2. Educate faculty about the process and what it means to them

3. Evaluate the timing of the process to see if a change there makes a difference

4. Do evaluations on-line reducing the need to take up class time

5. Act on the evaluation results

6. Inform the students of the evaluation results

\section{SUGGESTIONS FOR FUTURE RESEARCH}

Future research might consider looking at other schools within Hampton University to see if the findings are the same. A survey that tests the value of specific questions of the Hampton University Evaluation Form might also shed light on the topic.

\section{REFERENCES}

1. Abbott, R.D., Wulff, D.H., Nyquist, J.D., Ropp, V.A., \& Hess, C.W. (1990). Satisfaction with Processes of Collecting Students' opinions about Instruction: The Student Perspective. Journal of Educational Psychology. 82. pp. 201-206.

2. Abrami, P.C., d'Apollonia, S., \& Cohen, P.A. (1990). Validity of Student Ratings of Instruction: What we know and what we do not. Journal of Educational Psychology. 82. pp. 219-31.

3. Ahmadi, Mohammad; Helms, Marilyn M., \& Farhad Raiszadeh. (2001). Business Students' perceptions of Faculty Evaluations. The International Journal of Educational Management. Bradford: 2001. Vol. 15. Iss. 1; p. 12.

4. $\quad$ Anderson, Lorraine P. \& Shao, Lawrence P. (2002). Grading the Teachers. Biz-Ed. Nov/Dec. 2002. pp. 3639.

5. Anonymous. Evaluating Faculty: A Toolkit of Resources. Accounting Education News. Sarasota: Fall 2000. pp. 15.

6. $\quad$ Becker, W.E. \& Watts, M. (1999). The state of Economic education: How Department of Economics Evaluate Teaching. American Economics Review. 89. pp. 344-349.

$7 . \quad$ (2001) Teaching Economics at the Start of the $21^{\text {st }}$ century: Still chalk-and-chalk. American Economics Review 91: 441-451.

8. Blank, Rolf. (1978). Faculty Support for Evaluation of Teaching. Journal of Higher Education 49, (March/April), p.174.

9. Brickley, J.A. \& Zimmerman, J.L. (1999). Changing incentives in a multitask environment: evidence from a top-tier business school. Working paper.

10. Caldwell, J. \& Jenkins, J. (1985). Effects of the Semantic Similarityof items on Student Ratings of Instructors. Journal of Educational Psychology 77. p.383-393.

11. Cashin, W.E. (1988) Students Rating of Teaching: A Summary of the Research. IDEA Paper \#20. Manhattan, KS: Center for Faculty Evaluation and Development, Kansas State University. 
12. Cashin, W.E. (1995) Students Rating of Teaching: The Research Revised. IDEA Paper \#32. Manhattan, KS: Center for Faculty Evaluation and Development, Kansas State University.

13. Clayson, D.E. (1999). Students' Evaluation of Teaching Effectiveness: Some Implications of Stability. Journal of Marketing Education 21 (1). p.68-75.

14. Clayson, D.E. \& Haley, D.A. (1990). Student Evaluations in Marketing: What is actually being measured? Journal of Marketing Education 12 (3). P. 9-17.

15. Eble, Kenneth E. (1970). The Recognition and Evaluation of Teaching, Project to Improve College Teaching. (Salty Lake City, Utah).

16. Dommeyer, Curt J., Baum, Paul, and Hanna, Robert W. (2002). College Students' Attitudes toward Methods of Collecting Teaching Evaluations: In-class versus on-line. Journal of Education for Business. Washington: Sep/Oct 2002. Vol. 78. p. 11.

17. Dunegan, Kenneth J. \& Hrivnak, Mary W. (2003). Characteristics of Mindless Teaching Evaluations and the Moderating Effects of Image Compatibility. Journal of Management Education. Thousand Oaks. (June 20003). Vol. 27. p. 280.

18. Fay, Jack R., Ferrara, William L., \& Stryker, Judson P. (1993). The Quest for Quality in Business Schools. Management Accounting. Montvale. (December).

19. Gaski, J.F. (1987). On Construct Validity of measures of College Teaching Effectiveness. Journal of Educational Psychology. 79. 326-330.

20. Gomez-Mejia, L.R. \& Balkin, D.B. (1992). Determinants of Faculty Pay: An Agency Theory Perspective. Academy of Management Journal, 35 (5), p.921-955.

21. Houston, Franklin S. and Davis, James L. (1977). Learning and Grade Expectations: A Study of Instructor Evaluations. Journal of the Academy of Marketing Science 5, (Summer), p. 195-202.

22. Kanagaretnam, Kiridaran, Mathieu, Robert, \& Thevaranjan, Alex. (2003). An Economic Analyseis of the Use of Student Evaluations: Implications for Universities. Managerial and Decision Economics. (24). (Jan/Feb).

23. Kim, Chong, Earl, Damewood, \& Hodge, Norma. (2000). Professor Attitude: Its Effect on Teaching Evaluations. Journal of Management Education 24 (4). (August) p.458.

24. Layne, B.H., DeCristoforo, J.R., \& McGinty, D. (1999). Electronic versus Traditional Student Ratings of Instruction. Research in Higher Education. 40 (2). Pp. 221-232.

25. Lein, Charlos D. \& Merz, C. Michael. (1977-1978) Faculty Evaluation in Schools ob Business. Collegiate News and Views 31, p.21.

26. Lill, David J. (1986). The Development of a Standardized Student Evaluation Form. Academy of Marketing Journal, p. 242-253.

27. Marlin, J.W. (1987). Student Perception of End-of-course Evaluations. Journal of Higher Education 58. pp. 704-716.

28. Marsh, H. W. \& Roche, L. (1992). The Use of Student's evaluations and an Individually Structured Intervention to enhance University Teaching Effectiveness. Campbelltown, Australia: University of Western Sydney.

29. Marsh, H.W. \& Roche, L. (1987) Students' evaluations of university teaching: Research findings, methodological issues, and directions for future research. International Journal of Educational Research, 11. pp. 253-388.

30. Marsh, H.W. \& Roche, L.A. (1997). Making students' evaluations of teaching effectiveness effective: The critical issues of validity, bias and utility. American Psychologist, 52, 11871197.

31. Marsh, H.W. \& Roche, L.A. (2000). Effects of grading leniency and low workloads on students' evaluations of teaching: Popular myths, bias, validity or innocent bystanders? Journal of Educational Psychology, 92 . pp. 202-228.

32. Paswan, Audhesh K. \& Young, Joyce A. (2002). Student Evaluation of Instructor: A Nomological Investigation using Structural Equation Modeling. Journal of Marketing Education. Boulder. (December) Vol. 24, Iss. 3, p.193

33. Roush, D.C. (1976). Evaluating University Teaching. New Mexico State University, Published from Private funds. (July) p.1.

34. Seldin, P. (1985). Current Practices in Evaluating Business School Faculty. Pleasantville, NY: Pace University. 
35. _ (1993). The Use and Abuse of Student Ratings of Professors. Chronicle of Higher Education 21. (July), A40.

36. Sproull, L. \& Kiesler, S. (1991). Connections: New Ways of Working in the Networked Organization. Cambridge, MA: MIT Press.

37. Stapleton, Richard J. \& Murkison, Gene. (2001). Optimizing the fairness of student evaluations: A study of correlations between instructor excellence, study production, learning production, and expected grades. Journal of Management Education. (June). Pg. 269.

38. Tang, Thomas Li-Ping. (1997). Teaching Evaluation at a Public Institution of High Education: Factors related to the overall Teaching Effectiveness. Public Personnel Management. Washington. (Fall). Vol. 26, p.379. Wallace WA. (1998). Why the cost

39. Wallace, J.J. and Wallace, WA. (1998). Why the costs of student evaluations have long since exceeded their value. Issues in Accounting Education. 13. Pp. 443-447.

40. Watchell, H.K. (1994). A critique of Existing Practices for Evaluating Mathematics Instruction. Doctoral dissertation. University of Illinois at Chicago, 1994. Dissertation Abstracts International, 56, \# OIA. P. 0129.

41. Watchel, H.K. (1998). Student Evaluation of College Teaching Effectiveness: A brief review. Assessment and Evaluation in Higher Education, 23(2). Pp. 191-211.

\section{APPENDIX A: SURVEY FOR STUDENTS}

Based on previous information, the survey instrument is a 14 question 7 point likert scale as shown in Appendix A. Additional information has been added to the survey to capture gender, student classification, and ethnic orientation.

\section{Circle The Correct Response Below:}

Gender: $\quad$ M $\quad$ F

Classification: Junior Senior

Race: Caucasian African American Hispanic Asian Other

Please Determine Your Preferences On A Scale Of 1-7 To The Following Statements:
1
2
3
4
5
6
7

Strongly

Indifferent

Strongly

Agree

Disagree

\section{Please Place The Number Correspondint To The Scale To The Left Of Each Question (Numbers 1-7 Beside Each Question Below):}

1. I let Hampton University School of Business (HUSB) know of ways they can better serve my needs

2. I make constructive suggestions to HUSB to improve service

3. If I have a useful idea, I share it to someone at HUSB.

4. When I experience a problem, I let someone know so they can improve the service

5. If I notice a problem, I inform a faculty member even if it does not affect me.

6. If I receive good instruction from a faculty member, I let them know it.

7. If my grade is calculated wrong to my advantage, I still advise the professor.

8. I can easily compare one faculty member to another to determine who is best.

9. I have a hard time comparing faculty.

10. I can tell if a faculty member is good.

11. It is hard for me to tell if a faculty member is good

12. I am quite capable of distinguishing good faculty from poor faculty 
13. I can tell which faculty gives me the best instruction

14. I have a hard time judging faculty on factors like communications, style, organization, etc.

15. Teacher evaluation by students is valued by students

\section{APPENDIX B: SURVEY FOR ADMINISTRATOR, FACULTY, AND STAFF}

Based on previous information, the survey instrument is a 13 question 8 point Likert scale as shown in Appendix A. Additional information has been added to the survey to capture gender, student classification, and ethnic orientation.

\section{Circle The Correct Response Below:}

Gender: $\quad$ M $\quad$ F

Classification: Junior Senior

Race: $\quad$ Caucasian African American Hispanic Asian Other

Please Determine Your Preferences On A Scale Of 1-8 To The Following Statements:

$\begin{array}{llllllll}1 & 2 & 3 & 4 & 5 & 6 & 7\end{array}$

Strongly Indifferent Strongly N/A

Agree

Disagree

Please Place The Number Correspondant To The Scale To The Left Of Each Question (Numbers 1-8 Beside Each Question Below):

1. I let Hampton University School of Business (HUSB) know of ways they can

1. better serve my needs

2. I make constructive suggestions to HUSB to improve service

3. If I have a useful idea, I share it with someone at HUSB

4. When I experience a problem, I let someone know so they can improve the

5. service.

6. If I notice a problem, I inform someone even if it does not affect me.

7. I can easily compare one faculty member to another to determine who is best

8. I have a hard time comparing faculty.

9. I can tell if a faculty member is good.

10. It is hard for me to tell if a faculty member is good

11. I am quite capable of distinguishing good faculty from poor faculty.

12. I can tell which faculty gives the best instruction

13. I have a hard time judging faculty on factors like communications, style,

14. organization, etc.

15. 13. Faculty evaluation by students is valuable.

\section{Comments:}


NOTES 